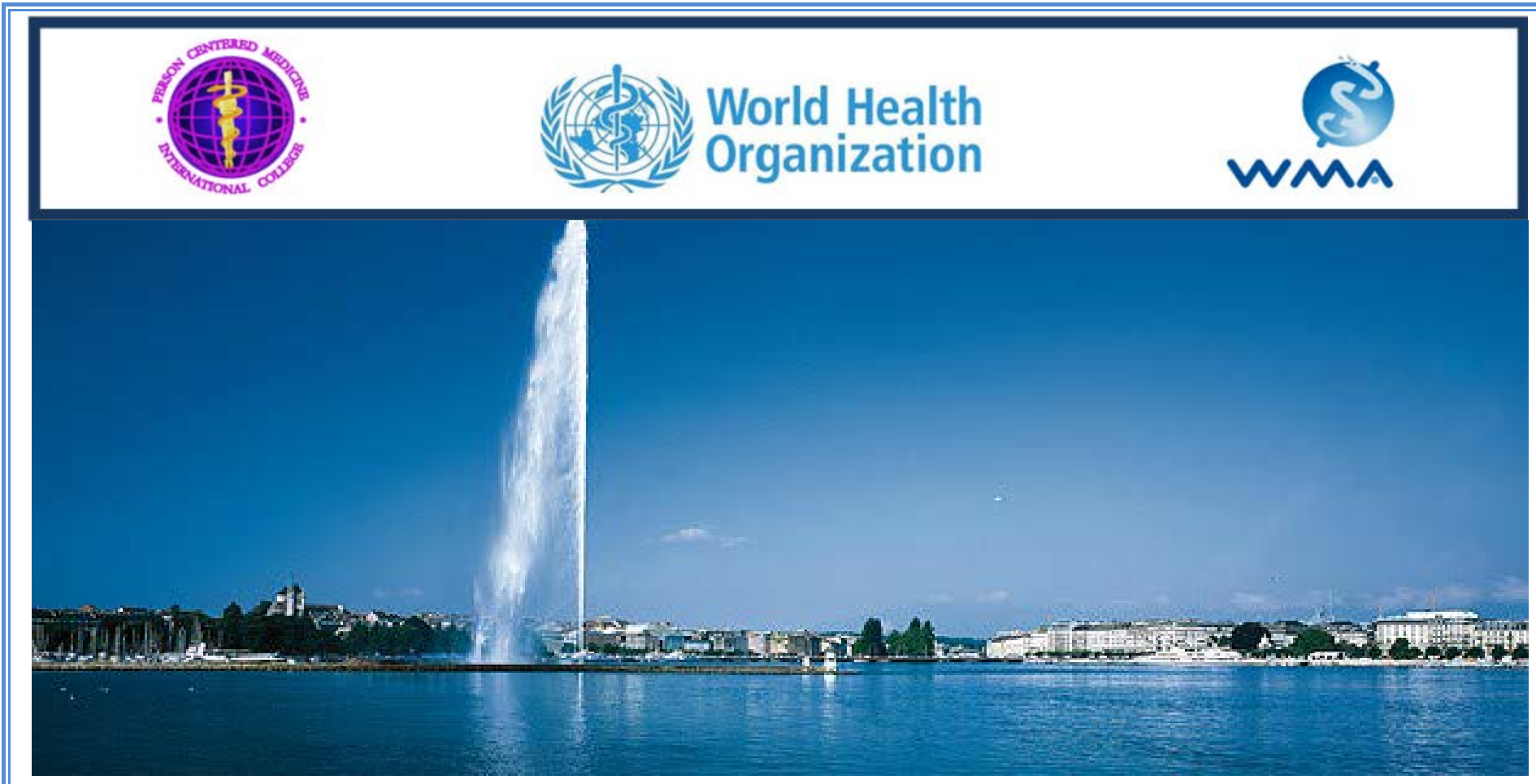

\title{
9th GENEVA CONFERENCE ON PERSON-CENTERED MEDICINE
}

\section{Person-Centered Integrated Care through the Life Course}

\author{
April 10 - 13, 2016 \\ Geneva University Hospital and World Health Organization \\ PROGRAM WORKSHEET
}

Organizing Committee: James Appleyard (President, International College of Person Centered Medicine), Ruth Wilson (Program Director), Juan E. Mezzich (Secretary General, International College of Person Centered Medicine), Michel Botbol (World Psychiatric Association Psychoanalysis in Psychiatry Section Chair), Tesfamicael Ghebrehiwet (Former Officer, International Council of Nurses), Jo Groves (Former Executive Director, International Alliance of Patients' Organizations), Ihsan Salloum (World Psychiatric Association Classification Section Chair), Sandra Van Dulmen (Former Officer, European Association for Communication in Healthcare), Jon Snaedal (ICPCM Advisor), Islene Araujo de Carvalho (WHO), Jim Campbell (WHO), and Nuria Toro Polanco (WHO).

Expected participants will be clinicians and scholars in medicine and related health disciplines as well as other health stakeholders. The registration fee is 450 Euros for persons residing in World Bank Group A (High Income Countries) and 300 Euros for persons from other countries. Documented full time students and members of patient and family associations will pay discounted half-rate fees.

ICPCM Continuing Professional Development (CME) Certificates will be issued

Abstracts deadline is March 15, 2016. Submissions should include title, authors with location and e-address, and a text of up to 250 words and two references connected to statements in the text. Abstracts should be preferably structured with objectives, methods, findings, discussion, and conclusions, and reflect either a systematic literature review, a data analysis, a consultation process, or a commentary.

Conference Secretariat: For further information as well as Registration and Abstract Forms, please visit www.personcenteredmedicine.org and write to the ICPCM Secretariat at Int'l Center for Mental Health, Mount Sinai School of Medicine, Fifth Ave \& 100 St, Box 1093, New York NY 10029, USA. E: ICPCMsecretariat@aol.com. 


\section{CONFERENCE PROGRAM}

PRE-CONFERENCE WORKMEETINGS ON PERSON-CENTERED MEDICINE:

SUNDAY APRIL 10, 2016

Venue: Geneva Univ Hospital, Auxilliary Halls one floor under the Marcel Jenny Auditorium, 4 rue Gabrielle-Perret-Gentil CH-1211 Geneva 4, Switzerland.

9:00AM - 5:00 PM Pre Conference Institutional Work Meetings

Chairs: Jon Snaedal (Reykjavik), Tesfa Ghebrebiwet (Alberta, Canada)

a. Person-centered Diagnosis: JE Mezich (New York), I Salloum (Miami), and Y Pongsupap (Bangkok) et al

b. 2016 Geneva Declaration Draft (Ruth Wilson (Kingston, Ontario, Canada)

c. Global Research Network: I Salloum (Miami) et al

d. Membership development: Joanna Groves (London) et al

e. Institutional Fund Raising: I Appleyard (London) et al

[10:45 - 11:00 AM, Coffee break]

[1:00 - 2:00 PM, Lunch break]

f. Books Workgroup: JE Mezzich (New York) et al

g. Person-centered Clinical Care Guiding Principles: I Appleyard (London), I Snaedal (Reykjavik), T Epperly (Boise, USA), S V an Dulmen (Nijmegen, Netherlands) et al

h. Other Workgroups

[4:45-5:00 PM, Coffee break]

5:00 - 6:00 PM IJPCM Editorial Board Meeting

6:00 - 7:30 PM ICPCM Board Meeting

CORE CONFERENCE FIRST DAY, MONDAY APRIL 11, 2016

Geneva University Hospital Marcel Jenny Auditorium and Auxiliary Halls

8:00 - 8:30 AM

$8: 30-8: 45$ AM
Registration and check-in

Conference Opening

Welcoming words from officers of the ICPCM (Jim Appleyard), Geneva University (Thierry Berney), World Health Organization (Islene Araijo), World Medical Association (Jon Snaedal), Wonca (Ruth Wilson, 9GC Program Director).

(Organizational Note: For most sessions, each presentation should last 8 minutes followed by 7 min clarifying Q\&As. There should be ample time at the end for general discussion and chairs' formulation of conclusions)

$8: 45-10: 15$ AM

10:15 - 10:45 AM
Plenary Symposium 1: Symposium on the full person-centered development of family medicine

Chairs: Jim Appleyard (London), Paul Grundy (New York)

- Family medicine: universal health coverage and primary care as essential building blocks of person centered medicine: Ruth Wilson (Kingston, Canada)

- How the person-centered medicine movement challenges family medicine: Ted Epperly (Boise, USA)

- The development of family medicine to meet the needs of persons and communities: past, present and future: Chris van Weel (Nijmegen, Netherlands)

- Person-centered family medicine in national health systems: Patterns and prospects: Yongyuth Pongsupap (Bangkok)

Coffee Break and

Poster Session:

- Patients' perspective in an evaluation study concerning professional task reallocation: Monique Bessems (Maastreich, Netherlands)

- A change in nursing home men's everyday life: a grounded theory study: Ann Karin Helgesen, Eli-Anne Skang, Vigdis Abrahamsen Grondal (Halden, Norway)

- Preoperative educational program for elective patients undergoing coronary artery bypass grafting (CABG): Mei Wa Lo, Kam Wai Hong, Sau Man Chan (Hong Kong) 
10:45 - 12:15 PM

$12: 15-1: 15 \mathrm{PM}$

1:15-2:45 PM

2:45 - 3:00 PM

3:00 - 4:30 PM
Plenary Symposium 2: Symposium on person-centered integrated care (PCIC) in families and children

Chairs: Ted Epperly (Boise, USA), Chris Van Weel (Nijmegen, Netherlands)

- Ethical issues in person centered care of children, whose interests prevail? : Jim Appleyard (London)

- Intersectoral (Health-Judicial Services) integration of person-centered care for children and adolescents: Michel Botbol (Brest, France).

- The role of "model husbands" in improving maternal \& new born health services in Burkina Faso: Janet Perkins (Geneva)

Lunch (open)

Parallel Sessions 1A: Symposium on person centered medical education and health systems enhancement

Chairs: Ruth Wilson (Kingston), David Gordon (WFME, Copenhagen)

- Mapping the global state of family medicine: John Parks (Lilongwe, Malawi)

- Person Centered Undergraduate Medical Education Implementation: UFV Model: Juan Perez-Miranda (Madrid)

- Educating young clinicians to provide patient centered care: Victor $\mathrm{Ng}$ (Toronto Canada)

- Thailand's young familuy doctors and their integration in the national health system: Y. Pongsupap (Bangkok, Thailand)

Parallel Session 1B: Symposium on PCIC for women

Chairs: Sandra Van Dulmen (Nijmegen, Netherlands), Joanna Groves (London)

- Women's health and the 2030 Agenda: Leaving no woman behind: Veronica Magar (WHO)

- The intersection of women's health and person centered care: Susan Pbillips (Kingston Ontario, Canada)

- Changing the paradigm: Woman-centered care throughout the life course: Margaret Usher Patel (Dorchester, UK)

- Determinants of maternal \& new-born health in Haiti: Cecilia Capello, Janet Perkins (Geneva)

Coffee Break

Parallel Session 2A: Symposium on PCIC for functionally challenged and special populations

Chairs: Michel Botbol (Brest, France), Tesfa Ghebrehiwet (Alberta, Canada)

- Best practices in communication with persons with IDD: Ian Casson (Kingston Ontario, Canada)

- Ethical issues in care for persons with IDD: Bill Sullivan (Toronto, Canada)

- Person-centered care for war-displaced refugees: Mohammed Abou-Saleh (London)

- The process of resilience and post traumatic stress disorder in migrants and refugees: Racbid Bennegadi (Paris)

- PCIC for multi-morbidity patients: Ibsan Salloum (Miami)

Parallel Session 2B: Symposium on PCIC systems and equity through the life course Chairs: Alberto Perales (Latin American Net. PCM, Lima), J Appleyard (London)

- Ethics and the social determinants of health: Eugenio Villar (WHO, Geneva)

- Contribution of employment to health over the life course: Minhat Rajput-Ray (Cambridge, UK)

- Contribution of social workers to systems equity: Terry Bamford (IFSW, London)

4:45 - 6:30 PM General Assembly of the International College of Person Centered Medicine (including presentation for discussion of the 2016 Geneva Declaration)

$7: 00-10: 00 \mathrm{PM}$
Conference Dinner 
9:00 AM - 10:30 AM Plenary Symposium 3: Symposium on person-centered integrated care (PCIC) in older age and at end of life

Chairs: Ted Epperly (Boise, US A), Glenn Brown (Kingston, Ontario, Canada)

- WHO strategy on ageing and health: Islene Araujo (WHO)

- Non -pharmacologic strategies to enhance communication with persons living with dementia: Susana Lauraine McCune (Seattle, USA)

- Global action for personhood in dementia: Jon Snaedal (Reykjavik)

- PCIC at the end of life: Otmar Kloiber (WMA, Ferney-Voltaire, France)

$10: 30-10: 45$ AM

10:45 AM - 12:15 PM

Coffee Break

Plenary Symposium 4: Symposium on PCIC and the organization, quality and safety of health systems

Chairs: Juan Mezich (New York), Ruth Wilson (Kingston, Ontario)

- Implementation of the WHO Framework on People-centered Integrated Health Services: Nuria Toro Polanco (WHO)

- How family medicine contributes to universal health care: Shannon Barkley (WHO)

- The future of Patient Centered Medical Homes: Paul Grundy (New York)

- Meso-level organization of primary care services to meet population needs: Glenn Brown (Kingston, Ontario, Canada)

- PCIC implementation in national health systems: Yongyuth Pongsupap (Bangkok)

12:15 - 1:15 PM

$1: 15-2: 45$ PM

Lunch (open)

Parallel Session 3A: Symposium on inter-specialty and inter-disciplinary professional relations for PCIC

Chairs: Jon Snaedal (Reykjavik), Maria Ammon (Berlin)

- Determining the composition of the primary care team: Ted Epperly (Boise, USA)

- Upstreaming NCD prevention: An interdisciplinary approach: Tesfa Ghebrehiwet (Alberta, Canada)

- Contributions of social workers to person-centered team work: Terry Bamford (IFSW, London)

- Inter-disciplinary work for person-centered care in epidemics: Rosa V allenas (WHO)

Parallel Session 3B: Symposium on research methodology for PCIC through the life course

Chairs: Ihsan Salloum (Miami), Thomas Schulze (Munich)

- Global "state of play" of person centered care: Ed Harding (London)

- Person-centered research designs: Sandra V an Dulmen (Nijmegen, the Netherlands)

- Person-centered diagnostic methodologies: Juan Mezzich (New York)

- Methodologies for evaluating person centered care through the life course: Levent Kirisci (Pittsburgh)

- Patient-Provider relationship for measuring primary care performance: George Southey (Oakville, Ontario, Canada)

2:45 - 3:00 PM

Coffee Break

3:00 - 4:30 PM

Parallel Session 4A: Symposium on health stakeholders' engagement and perspectives for PCIC through the life course

Chairs: Jim Appleyard (London), Mohammed Abou-Saleh (London)

- Enhancing patients' use of health records: Joanna Groves (London)

- Nursing contributions to PCIC through the life course: Tesfa Ghebrehinvet (Alberta, Canada)

- Person-centered research use of health records: Levent Kirisci (Pittsburgh)

- Patients' and family caregivers' goals for care during transitions out of the hospital: Eric Coleman (Aurora, Colorado, USA) 
Parallel Session 4B: Brief Oral Presentations 1: Person Centered Mental Health and Positive Health

Chairs: John Cox (Cheltenham, UK), H-R Pfeifer (Zurich)

- The Whole Heals: Humanity's one body and healing of the person: Kondotbra George (Kerala, India)

- Body oriented psychotherapy in the understanding of dynamic psychiatry: Maria Ammon (Berlin)

- Emotional resonance and body experience in analytical-structural dance therapy: Ilse Burbiel (Munich)

- Illness, disease, understanding the person and the goals of medicine: Joseph Burley (Kingston, Ontario)

- Review dialogues as an opportunity to develop life course specific health goals: Ottomar Bahrs, Susanne Heim, Karl-Heinz. Henze, Franziska Löwenstein (Göttingen, Germany)

- Person centered recovery planning at Austin State Hospital and the integration of peer support into this: Eulon Ross Taylor, Noah Abdenour (Austin, Texas)

$4: 30-4: 45$ PM
$4: 45-6: 45$ PM

Break

Parallel Session 5A: Antoine Besse and Jitendra Trivedi Memorial Symposium on

Person Centered Psychiatry and Mental Health for PCIC in the Life Course

Chairs: Afral Javed (Nuneaton, UK), Michel Botbol (Brest, France)

$\square$ WPA Sections' brief perspectives

- Biological Psychiatry: The challenges of multi-morbidity over the life course and the need for person-centered integrated care: Helen Millar (Dundee, Scotland)

- Early Career Psychiatrists: Views on person centered medicine: Florian Riese (Zurich)

- Genetics in Psychiatry: Person-centered approaches and psychiatric genetics: Thomas Schulze (Munich)

- Preventive Psychiatry: Perspectives on Person-centered integrated care: Nikos Christodoulou (Nottingham, UK)

- Spirituality and Religion: the new realities for medical practice in the twenty-first century: J Cox (Cheltenham, UK)

$\square$ Round of Presenters' Comments on set of presentations made

$\square$ Chairs' conclusions and next steps for WPA Section activities on person centered psychiatry

Parallel Session 5B: Brief Oral Presentations 2: Person Centered Health Care Chairs: Tesfa Ghebrebiwet (Alberta, Canada), Sandra Van Dulmen (Nijmegen, Netherlands)

- The person centered change of the health paradigm through the caregiver's person and community: Giuseppe R. Brera (Milan)

- Extending simulation-based learning experiences to patients with chronic health conditions: Eric Coleman, Sung-Joon Min (Aurora, Colorado)

- The impact of person-centered care on residents' perceptions of care quality in nursing homes: an intervention study: Vigdis Abrahamsen Grondabl, Liv Berit Fagerli, Ann Karin Helgesen (Halden, Norvay)

- Developing an evidence-based educational intervention protocol for improving glaucoma patients' eye drop therapy adherence and outcomes: Suk Kwan, Victoria Ho, Mi Ling, Eliza Wong (Tuen Mun, Hong Kong)

- Patient-centered integrated education program for surgical patients receiving trans urethral resection of prostate: Hoi Ling Shering Sung, Conny Chan (Hong Kong)

- Measuring health literacy among very low literate people: a feasibility study with the HLS-EU questionnaire: Hannelore Storms (Diepenbeek, Belgium)

- Information and communication technology for enabled person-centered care in the "Big Five" chronic conditions: scoping review: Sabine E. Wildevuur (Amsterdam)

7:00 PM

Dinner (On Your Own with Suggested Networking Opportunities)

CORE CONFERENCE THIRD DAY, WEDNESDAY April 13, 2016

WHO Headquarters, Salle G 
9:00 AM - 10:30 AM Plenary Symposium 5: Symposium on Global Health Workforce for PCIC through the life course

Chairs: Jim Appleyard (London), Otmar Kloiber (WMA, Ferney-Voltaire, France)

- Preparing the health workforce for PCIC: Issues through the life course: Jim Campbell (WHO)

- How medical schools are recruiting and preparing health professionals for PCIC: David Gordon (WFME, Copehagen)

- The medical student and the professor/mentor as persons in a new mentorship program at a Peruvian medical school: Alberto Perales (Latin American Network for PCM, Lima)

- Prospects for person-centered health professional education in Asian populations: Roy Kallivayalil (Kerala, India)

- Family medicine and primary care: how do the two relate to PCIC?: Ruth Wilson (Kingston, Canada)

10:30 -10:45 AM

Coffee Break

10:45 AM - 11:45 AM Plenary Closing Session (including presentation for adoption of the 2016 Geneva

Declaration)

Chairs: Jim Appleyard and Juan Merzich (ICPCM)

$11: 45-12: 00 \mathrm{M}$

Break and Group Photograph

12:00 - 2:30PM

WHO Special Session on Collaboration for the Implementation of WHO Global Strategies and Frameworks (by invitation)

[Light Lunch]

Chairs: Jim Appleyard (ICPCM), Islene Araujo (WHO), and Jim Campbell (WHO)

- Brief presentation on WHO Global Strategy and Action Plan on Ageing and Health: Ritu Sadana (WHO)

- Brief presentation on WHO Framework on People Centered Integrated Health Services: Nuria Toro Polanco (WHO)

- Brief presentation on WHO Global Strategy on Global Health Workforce: Jim Campbell (WHO)

- Contributions from the ICPCM and Collaborating Organizations.

- Conclusions and Next Collaborative Steps 